\title{
Clinico-demographic profile among female with alcohol related problems in the eastern part of Nepal
}

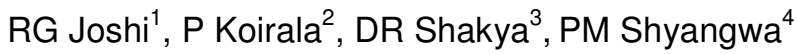 \\ Department of Psychiatry, B.P. Koirala Institute of Health Sciences
}

\begin{abstract}
Background: Alcohol can affect anyone. It is not prejudicial towards any race, colour, sex, religion or economic level. It affects individual's life, personal relationship, health and occupational functioning. ${ }^{1}$ Alcohol is estimated to cause a net harm of $3.7 \%$ of all deaths and $4.4 \%$ of the global burden of disease. ${ }^{3}$ This study will provide baseline data and pave way for further studies and broaden the implication for the management and control of alcohol related problems in female. Objective: To provide baseline data about the clinico-demographic profile of the female with alcohol related problems. Method: A semi- structured proforma was designed to collect the data. A total of 51 female patients participated in the study after giving their written informed consent. Result: The maximum number of patients were in the age group of 41-50 (37.2\%); followed by the age group 31-40 (31.3\%). The mean age was $42.63 \pm 11.11$ years. The predominant caste was Rai 33.3\% followed by Limbu 19.6\%. All the cases were Hindus by religion. Most of the cases were married (82.3\%) housewives, (56.8\%) with nuclear family $(68.6 \%)$ and illiterate (58.8\%). The age of first alcohol intake was $17.45 \pm 9.45$ years, total duration of use $24.86 \pm 14.7$. Family custom (56.88\%) was the most common reason for the first use of alcohol. Local distilled alcohol was preferred (58.8\%) and $72.5 \%$ used to drink alone. The most common presenting complaint was auditory hallucination (12.36\%). Conclusion: The most affected age group was at the peak of their economic and reproductive abilities. Most of the patients were illiterate and jobless. A comprehensive educational awareness program about alcohol use and its effects on the female as a whole, with special attention to pregnancy and lactation is to be undertaken at the community level, with maximum female participation. It is important to recognize and realize that women have unique aspects to their alcohol problems and to understand the complex interplay of roles they have to play in the form of daughter, mother, wife, in-law and manager of the household activities including taking care of children as

Address for correspondence well as elderly at home and plan accordingly.

Dr. Rinku Gautam Joshi

Assistant Professor

Department of Psychiatry

B.P. Koirala Institute of Health Sciences, Dharan

E-mail: rinkugautam@hotmail.com


Keywords: Alcohol, clinical profile, demographic profile, female

\section{Introduction}

Alcohol can affect anyone. It is not prejudicial towards any race, colour, sex, religion or economic level. It affects individual's life, personal relationship, health and occupational functioning. ${ }^{1}$ Prevalence of alcohol use disorders in adults was estimated to be around $1.7 \%$ globally $(2.8 \%$ for men, $0.5 \%$ for women). ${ }^{2}$ About 2 billion people worldwide who consume alcohol and 76.3 million with diagnosable alcohol use disorder. Alcohol is estimated to cause a net harm of $3.7 \%$ of all deaths and $4.4 \%$ of the global burden of disease. ${ }^{3}$

Alcohol consumption has shown a decline in developed countries in recent times, but it has been rising rapidly in developing countries including Nepal. ${ }^{4}$ Per capita alcohol consumption among adults ( $\geq 15$ years) in Nepal, is 0.2 litres of pure alcohol. ${ }^{5}$ The prevalence of alcohol use in Nepal was $75.0 \%$ in urban and $66.7 \%$ in rural area. There were $72.7 \%, 77.0 \%$ and $59.9 \%$ males from Mountain, Hill and Terai region. ${ }^{6}$ About 4 lakh persons are suffering from alcohol related disorders.

The prevalence of alcohol dependence in Dharan is $25.8 \% .^{7}$ The estimated prevalence of alcohol consumption among females of Dharan was $17 \% .^{8}$ BP Koirala Institute of Health Sciences (BPKIHS), Dharan provides health services to the population with high prevalence of alcohol use, but only 6 out of the 39 patients admitted in in-patient ward of psychiatry department with ADS, were female in year 2007/08 AD. ${ }^{9}$ This also shows though the prevalence of alcohol use in female is high in this area, the health seeking attitude is less. In BPKIHS, alcohol and substance related problems were the most common cause for psychiatric emergency consultations. $^{10}$

Even with the high prevalence of alcohol use in female in this area, the systematic study on female alcohol use has not been done. The quality of life of family members mainly depends on mother. If mother develops alcohol related problems it may adversely affect the family as a whole directly, than the father developing alcohol related problems. This study will provide baseline data about the clinico-demographic profile of the female with alcohol related problems and pave way for further studies and broaden the implication for the management and control of alcohol related problems in female.

\section{Methods}

This was a hospital based cross sectional descriptive study. The selected participants were consecutive female patients with alcohol related problem who came under the health 
care service of psychiatry, consultation liaison and other departments of BPKIHS, Dharan, scoring two or more scores in T-ACE questionnaire, those who were in abstinence for two or less than two months, those who gave informed written consent to participate in the study and were more than $16 \mathrm{yrs}$. Patient with multiple substance dependence, or who were severely ill and could not give informed consent and did not having reliable care taker to consent were excluded.

A semi-structured proforma was designed to collect the data. A total of 51 female patients participated in the study after giving their written informed consent. The study duration was from 2009 to 2010. The ethical approval for the study was obtained from the Institute's Ethical Board.

The data was analysed using SPSS version 14.0.

\section{Results}

A total number of 51 patients were included. The maximum number of patients were in the age group of $41-50$ (37.2\%); followed by $31-40$ (31.3\%). The mean age was $42.63 \pm$ 11.11 years (range 22-72). The predominant caste was Rai. Most were married (82.3\%) with nuclear family (68.6\%). Husband accompanied in $41.1 \%$.

Table 1: Distribution of socio demographic characteristics

\begin{tabular}{|l|l|l|l|}
\hline Characteristics & Category & Frequency (n) & Percent (\%) \\
\hline \multirow{4}{*}{ Age (in years) } & $21-30$ & 7 & 13.73 \\
\cline { 2 - 4 } & $31-40$ & 16 & 31.37 \\
\cline { 2 - 4 } & $41-50$ & 19 & 37.26 \\
\cline { 2 - 4 } & $51-60$ & 6 & 11.76 \\
\cline { 2 - 4 } & $61-70$ & 2 & 3.92 \\
\cline { 2 - 4 } & $71-80$ & 1 & 1.96 \\
\hline \multirow{5}{*}{ Caste } & Brahmin & 3 & 5.88 \\
\cline { 2 - 4 } & Kshatriya & 3 & 5.88 \\
\cline { 2 - 4 } & Newar & 2 & 3.92 \\
\cline { 2 - 4 } & Gurung & 2 & 33.33 \\
\cline { 2 - 4 } & Rai & 17 & 1.84 \\
\cline { 2 - 4 } & Magar & 4 & 1.96 \\
\cline { 2 - 4 } & Limbu & 10 & 1 \\
\hline
\end{tabular}




\begin{tabular}{|l|l|l|l|}
\hline \multirow{4}{*}{ Marital status } & Other & 9 & 17.65 \\
\hline & Unmarried & 4 & 7.84 \\
\cline { 2 - 4 } & Married & 42 & 82.35 \\
\cline { 2 - 4 } & Separated & 2 & 3.92 \\
\cline { 2 - 4 } & Widow & 3 & 5.88 \\
\hline \multirow{4}{*}{ Family type } & Nuclear & 35 & 68.63 \\
\cline { 2 - 4 } & Joint & 14 & 27.45 \\
\cline { 2 - 4 } & Broken & 2 & 3.92 \\
\hline \multirow{5}{*}{ Guardian / Informant } & Father & 1 & 1.96 \\
\cline { 2 - 4 } & Mother & 2 & 3.92 \\
\cline { 2 - 4 } & Brother & 2 & 3.92 \\
\cline { 2 - 4 } & Sister & 7 & 13.73 \\
\cline { 2 - 4 } & Husband & 21 & 41.18 \\
\cline { 2 - 4 } & Son & 9 & 17.65 \\
\cline { 2 - 4 } & Daughter & 5 & 9.80 \\
\cline { 2 - 4 } & Relatives & 3 & 1.96 \\
\cline { 2 - 4 } & Self & 1 & $\mathbf{1 0 0}$ \\
\hline Total & & $\mathbf{5 1}$ & \\
\hline
\end{tabular}

Table 2: Distribution of subjects by education, occupation, monthly income and geographical distribution

\begin{tabular}{|l|l|l|l|}
\hline \multicolumn{1}{|c|}{ Character } & \multicolumn{1}{|c|}{ Category } & Frequency (n) & Percent (\%) \\
\hline \multirow{4}{*}{ Education } & Illiterate & 30 & 58.82 \\
\cline { 2 - 4 } & Can read and write & 7 & 13.73 \\
\cline { 2 - 4 } & Class I - III & 7 & 13.73 \\
\cline { 2 - 4 } & Class IV - VII & 4 & 7.84 \\
\cline { 2 - 4 } & Class VIII - SLC & 3 & 5.88 \\
\hline \multirow{5}{*}{ Occupation } & Business & 12 & 23.53 \\
\cline { 2 - 4 } & Farmer & 7 & 13.73 \\
\cline { 2 - 4 } & Labour & 1 & 1.96 \\
\cline { 2 - 4 } & Housewife & 29 & 56.86 \\
\cline { 2 - 4 } & Tailor & 2 & 3.92 \\
\hline
\end{tabular}




\begin{tabular}{|l|l|l|l|}
\hline \multirow{4}{*}{ Monthly income in rupees } & $\leq 10000$ & 9 & 17.67 \\
\cline { 2 - 4 } & $11000-20000$ & 40 & 78.43 \\
\cline { 2 - 4 } & $>20000$ & 2 & 3.9 \\
\hline \multirow{5}{*}{ Districts } & Sunsari & 27 & 52.94 \\
\cline { 2 - 4 } & Morang & 6 & 11.76 \\
\cline { 2 - 4 } & Jhapa & 5 & 9.8 \\
\cline { 2 - 4 } & Dhankuta & 3 & 5.88 \\
\cline { 2 - 4 } & Panchthar & 2 & 3.92 \\
\cline { 2 - 4 } & Udayapur & 2 & 3.92 \\
\cline { 2 - 4 } & Khotang & 1 & 1.96 \\
\cline { 2 - 4 } & Bhojpur & 1 & 1.96 \\
\cline { 2 - 4 } & Sankhuwasabha & 1 & 1.96 \\
\cline { 2 - 4 } & Saptari & 1 & 1.96 \\
\cline { 2 - 4 } & Taplejung & 1 & 77.78 \\
\cline { 2 - 4 } & Tehrathum & 1 & 22.22 \\
\hline \multirow{5}{*}{ Sunsari district } & Dharan & 21 & $\mathbf{1 0 0}$ \\
\hline Total & Municipality & 6 & \\
\cline { 2 - 4 } & Outside Dharan & 6 & \\
\hline
\end{tabular}

Thirty cases (58.8\%) were illiterate. Seven cases (13.7\%) had no formal education. No one educated more than SLC. About 56.8\% were housewives and $23.5 \%$ were involved in business. Most had income range of 1100020000 (78.4\%). Twenty seven (52.9\%) were from Sunsari, $77.78 \%$ from Dharan.

Table 3: Distribution of subject by presenting complaints

\begin{tabular}{|l|c|c|}
\hline \multicolumn{1}{|c|}{ Presenting complaints } & Frequency (n) & Percent (\%) \\
\hline Auditory hallucination & 11 & 12.36 \\
\hline Convulsion & 7 & 7.87 \\
\hline Epigastric pain & 6 & 6.74 \\
\hline Decrease sleep & 6 & 6.74 \\
\hline Fever & 6 & 6.74 \\
\hline
\end{tabular}




\begin{tabular}{|l|c|l|}
\hline To quit alcohol & 5 & 5.62 \\
\hline Decrease appetite & 5 & 5.62 \\
\hline Fearfulness & 5 & 5.62 \\
\hline Talkativeness & 5 & 5.62 \\
\hline Vomiting & 4 & 4.49 \\
\hline Visual hallucination & 3 & 3.37 \\
\hline Black stool & 3 & 3.37 \\
\hline Low mood & 3 & 3.37 \\
\hline Blood vomit & 2 & 2.25 \\
\hline Attempted suicide & 2 & 2.25 \\
\hline Tingling sensation of legs & 2 & 2.25 \\
\hline Burn & 1 & 1.12 \\
\hline Weakness & 1 & 1.12 \\
\hline Repeated hand washing & 1 & 1.12 \\
\hline Decreased functioning & 1 & 1.12 \\
\hline Abnormal behaviour & 1 & 1.12 \\
\hline Burning micturition & 1 & 1.12 \\
\hline Epistaxis & 1 & 1.12 \\
\hline Swelling of legs & 1 & 1.12 \\
\hline Abdominal distension & 1 & 1.12 \\
\hline Jaundice & 1 & 1.12 \\
\hline Bleeding gum & 1 & 1.12 \\
\hline Loss of weight & 1 & 1.12 \\
\hline Cough & 1 & 1.12 \\
\hline Irritability & 1.12 \\
\hline Total & 1 & \\
\hline & 1 & 120 \\
\hline
\end{tabular}

The most common presenting complaint was auditory hallucination in $12.36 \%$.
Multiple response categories - one respondent may have one or more responses 
Table 4: Distribution by reason for first use, experience in first use, type of alcohol use and style of use

\begin{tabular}{|c|c|c|c|}
\hline Character & Category & Frequency (n) & Percent (\%) \\
\hline \multirow{8}{*}{ Reason for $1^{\text {st }}$ use } & Pregnancy & 2 & 3.92 \\
\hline & Puerperium & 4 & 7.84 \\
\hline & Curiosity & 1 & 1.96 \\
\hline & Family custom & 29 & 56.88 \\
\hline & Friends & 10 & 19.6 \\
\hline & Fun & 3 & 5.88 \\
\hline & For energy & 1 & 1.96 \\
\hline & Relieve tension & 1 & 1.96 \\
\hline \multirow{8}{*}{ Experience in $1^{\text {st }}$ use } & Bitter & 3 & 5.89 \\
\hline & Tasty & 5 & 9.8 \\
\hline & Sweet & 6 & 11.76 \\
\hline & Doesn't remember & 9 & 17.65 \\
\hline & Euphoria & 12 & 23.53 \\
\hline & Pleasant & 11 & 21.57 \\
\hline & Unpleasant & 4 & 7.84 \\
\hline & Energy increase & 1 & 1.96 \\
\hline \multirow{5}{*}{ Type of alcohol use } & Whisky & 1 & 1.96 \\
\hline & All & 11 & 21.57 \\
\hline & Local distilled & 30 & 58.82 \\
\hline & Local fermented & 8 & 15.69 \\
\hline & Rum & 1 & 1.96 \\
\hline \multirow{5}{*}{ Style of Use } & Alone & 37 & 72.55 \\
\hline & With husband & 5 & 9.80 \\
\hline & $\begin{array}{l}\text { With family } \\
\text { members }\end{array}$ & 5 & 9.80 \\
\hline & with friends & 4 & 7.84 \\
\hline & Total & 51 & 100 \\
\hline
\end{tabular}


Family custom (56.8\%) was the commonest reason to start alcohol. Euphoria (23.5\%) was experienced in the first use. Local distilled
(58.8\%) was the preferred drink and $72.5 \%$ drink alone. All had continuous pattern of use.

Table 5: Distribution by age of first alcohol use, total duration of alcohol use and duration of daily alcohol use

\begin{tabular}{|c|c|c|c|}
\hline Character & Category & Frequency (n) & Percent (\%) \\
\hline \multirow{5}{*}{ Age of $1^{\text {st }}$ use (in years) } & $<11$ & 16 & 31.38 \\
\hline & $11-20$ & 19 & 37.25 \\
\hline & $21-30$ & 12 & 23.53 \\
\hline & $31-40$ & 3 & 5.88 \\
\hline & $51-60$ & 1 & 1.96 \\
\hline \multirow{7}{*}{ Total duration of use (in years) } & $<11$ & 10 & 19.61 \\
\hline & $11-20$ & 11 & 21.57 \\
\hline & $21-30$ & 15 & 29.41 \\
\hline & $31-40$ & 9 & 17.65 \\
\hline & $41-50$ & 3 & 5.88 \\
\hline & $51-60$ & 2 & 3.92 \\
\hline & $61-70$ & 1 & 1.96 \\
\hline \multirow{6}{*}{ Duration of daily use (in years) } & $<11$ & 22 & 43.14 \\
\hline & $11-20$ & 18 & 35.29 \\
\hline & $21-30$ & 6 & 11.77 \\
\hline & $31-40$ & 3 & 5.88 \\
\hline & $41-50$ & 1 & 1.96 \\
\hline & $51-60$ & 1 & 1.96 \\
\hline \multirow{6}{*}{ Last intake (in days) } & $\leq 1$ & 9 & 17.66 \\
\hline & $1-7$ & 31 & 60.78 \\
\hline & $8-14$ & 3 & 5.88 \\
\hline & $15-21$ & 1 & 1.96 \\
\hline & $22-28$ & 5 & 9.8 \\
\hline & $28-35$ & 2 & 3.92 \\
\hline Amount of ethanol use (in $\mathrm{ml}$ ) & $150-350$ & 14 & 27.46 \\
\hline
\end{tabular}




\begin{tabular}{|l|c|c|c|}
\hline \multirow{4}{*}{} & $351-550$ & 12 & 23.53 \\
\cline { 2 - 4 } & $551-750$ & 16 & 31.37 \\
\cline { 2 - 4 } & $751-950$ & 5 & 9.8 \\
\cline { 2 - 4 } & $951-1150$ & 1 & 1.96 \\
\cline { 2 - 4 } & $1151-1350$ & 3 & 5.88 \\
\hline & Total & $\mathbf{5 1}$ & $\mathbf{1 0 0}$ \\
\hline
\end{tabular}

Most of the cases started drinking in the age group 11-20 (37.2\%); 29.4\% had been drinking for 21-30 years; $43.1 \%$ had been drinking daily for less than 11 year. Almost
$31.3 \%$ were consuming $551-750 \mathrm{ml}$ of ethanol per day. Last intake of alcohol in $60.78 \%$ was between 1 to 7 days.

Table 6: Mean, standard deviation, maximum, minimum and range of age of first use, total duration of use, duration daily of use, amount of ethanol and last intake

\begin{tabular}{|l|c|c|c|c|c|}
\hline \multicolumn{1}{|c|}{ Category } & Mean & SD & Min. & Max. & Range \\
\hline Age of first use (in years) & 17.45 & 9.45 & 5 & 53 & 48 \\
\hline Total duration of use (in years) & 24.86 & 14.7 & 4 & 63 & 59 \\
\hline Duration of daily use (in years) & 15.09 & 11.93 & 1 & 51 & 50 \\
\hline Amount of ethanol (in ml) & 552.25 & 282.43 & 150 & 1200 & 1050 \\
\hline Last intake (in days) & 6.44 & 8.82 & 0 & 30 & 30 \\
\hline
\end{tabular}

\section{Discussion}

This is hospital based cross sectional study. Similar studies were carried out in this institute in 2000 and NIMHANS, India in 1995 where the duration was 16 months and12 years and the cases were 50 and 71 respectively. ${ }^{11,}{ }^{12}$ In India, there were 71 cases in 12 years; this may be because the social tolerance to alcohol use is quite high in Nepal.
All the cases were from the Eastern Development Region. Geographically, Nepal is divided into Mountains, Hill and Terai Region. According to the 2001 Census, the Mountains accommodates $7.3 \%$ whereas Hills and Terai $44.3 \%$ and $48.4 \%$ respectively..$^{13}$ In this study, $76.5 \%$ were from Terai Region; $19.6 \%$ from Hills and 3.9\% from Mountains. This hospital is in Sunsari District so $52.9 \%$ were from Sunsari and among them, $77.8 \%$ from Dharan. 
In Nepal, 20.2\% are Mongoloid race, 15.8\% Chhetri, 13.3\% Brahmin, 6.7\% Tharu and $5.4 \%$ Newar. $^{13}$ In our study, $64.7 \%$ were of Mongolioid and among them Rai were 17 (33.3\%) and Limbu 10 (19.6\%) which is consistent with Dharan's ethnic distribution. Hill native castes (Matawali) like Rai, Limbu, Tamang, Magar, Sherpa, Gurung and Hill occupational castes (Sarki, Bishwokarma) are tradional alcohol users. Major Hill castes (Tagadhari) like Brahmins, Chhetris, Newars are traditional non users, though the latter are liberal towards alcohol use. In this study, Matawali were $66 \%$ and Tagadhari were $15.7 \%$ which is in contrast with previous study where significant number of non-users presented with ADS. ${ }^{14}$ This could be because our study included only females. Our finding is consistent with the study on female alcohol users where the prevalence rate in the Hill Native Caste was $23.4 \%$, Hill Occupational Caste $14.7 \%$ and Major Hill Caste $9.0 \%{ }^{8}$

In Nepal the highest alcohol use was observed among Buddhist 30.2\%, followed by Hindu $26.4 \%$ and Christian $14 \%{ }^{7}$ Majority of the Matawali follow the Buddhism, that could be the reason for so. A similar study showed Hindu 78.3\%, Buddhist 15.7\%; and Christian. ${ }^{14}$ A study on female showed Kiranti $26 \%$, Buddhist $22.2 \%$ and others $0.6 \% .^{8}$ But in this study all cases were Hindus

Most patients were in the age group of 41- 50 (37.2\%); followed by $31-40$ years $(31.3 \%)$.
The finding is similar to the study by Sharma ${ }^{11}$ and Shakya ${ }^{14}$ where the age group was 35-44 and 30-49 years respectively. Similar finding were found in other study done in a community of Western Nepal. ${ }^{15}$ Another study showed reproductive age group (15-49) constituted 81.3\%; but the prevalence was maximum in the age group 55-64 (39.9\%). ${ }^{8}$ This shows that the alcohol use affects the economically productive and the reproductive age group in the females.

Majority (82.3\%) were married, 5.8\% widow, $3.9 \%$ separated and $7.8 \%$ unmarried which is different from a community study by Niraula SR et al, where the unmarried were $31 \%$; $58.8 \%$ married, $8.8 \%$ widow and $1.1 \%$ separated/divorced. Most belonged to nuclear family $68.6 \%$ and $92 \%$ were accompanied by close relatives. The family support and the acceptance in the family appear to be maintained where in NIMHANS study fewer stable relationships (7.8\% divorce/ separated) found. ${ }^{12}$

Majority (58.8\%) were illiterate and $56.9 \%$ were housewife. Seventy-two percent didn't have any formal education and only $13.7 \%$ had education beyond primary level. Similar finding was seen in a community study where ADS prevalence was highest in the illiterate group (35.8\%) and decreased progressively with higher education (16.8\%). ${ }^{14}$ The common occupation was business $23.5 \%$ of brewing and selling homemade alcohol, 
making higher chance of exposure and further problem. The finding is similar to the finding among females in Dharan, where $56.1 \%$ were housewife. ${ }^{8}$

Most of them (78.4\%) from middle class family. Though a larger proportion of regular drinkers were from higher socio-economic status, frequency of heavy drinking were more with low socio-economic group. ${ }^{16}$ In NIMHANS study, $85 \%$ belonged to lower socioeconomic status. ${ }^{12}$

Local distilled preparation 'Raksi' (58.8\%) was the preferred drink. This is similar to the finding by Dhital R. ${ }^{17}$ In NIMHANS study, the preferred beverage consisted of spirit (brandy, whisky or locally made). ${ }^{12}$ There was solitary drinking in women than men who drink away from home with the same sex peers. ${ }^{12}$ In this study, $72.5 \%$ used to drink alone. All the cases had continuous pattern of use. This is in contrast with NIMHANS study, where $20.8 \%$ had bingeing. ${ }^{12}$

Studies by Dawson $\mathrm{DA}^{18}$ and Capone $\mathrm{C}^{19}$ showed family history of alcohol use is associated with early onset of alcohol use and alcohol use related disorder. But another study by Zaje et. al. ${ }^{20}$ showed no association. In this study, family custom (56.8\%) followed by friends' influence (19.6\%) were the reason to start alcohol use. Age at first use has been proven to be an important predictor of developing ADS and age of more than 40 years had a decreased risk of developing
ADS. $^{21}$ In our study, 37.2\% started drinking in the age group $11-20$ followed $31.3 \%$ by less than 11 years age group. So, the most patients $(68.5 \%)$ started drinking alcohol before the age 20 . The mean age to start drink was $17.45 \pm 9.45$ years which is similar to study in Germany (16.5 \pm 4.1 years). ${ }^{22}$

Thirty percent had been drinking for 21-30 years followed by $21.5 \%$ for $11-20$ years. The mean total duration of drinking was $24.86 \pm 14.7$ years. Forty three percent had been drinking daily for less than 11 years followed by $35.3 \%$ for $11-20$ years. The mean duration of daily use was $15.09 \pm 11.93$ years. In NIMHANS study, duration of daily use from 1.5 months to 25 years and the mean age at the onset of dependence was $32 \pm 9.3$ years $^{12}$ and in our study it was $27.53 \pm 10.85$ and was $28.3 \pm 9.6$ in Germany ${ }^{22}$ which are comparable.

Almost one third (31.3\%) were consuming 551-750 $\mathrm{ml}$ of ethanol per day. The mean ethanol consumed was $552.25 \pm 282.43 \mathrm{ml}$. Daily consumption was $162.4 \pm 100.07 \mathrm{ml}$ in India ${ }^{12}$ and $360.76 \pm 250.63 \mathrm{ml}$ in Germany ${ }^{22}$. Denmark study revealed the risk of developing alcoholism increased significantly even by very low intakes of alcohol in women than men. ${ }^{23}$

The most common presenting complaint was auditory hallucination (12.3\%) followed by convulsion (7.8\%). Only $5.6 \%$ came for the purpose of quitting alcohol. This is in contrast 
to the study by Shakya DR, where behavioral problem was most $18.5 \%$ and $15.7 \%$ had come to quit alcohol. ${ }^{14}$ The reason for difference though conducted in the same institute, our study had only female. In NIMHANS $75.3 \%$ presented as psychiatric disorders as presenting complaints, among them depression $24.7 \%$ and alcohol related psychosis $28.6 \%$ and only $15.6 \%$ were self motivated to quit alcohol. ${ }^{12}$

The limitations of the study were the sample size, the exact strength of the homemade alcohol was not known, and study was done in patients seeking help from BPKIHS. So, the study may not represent the general population and the results may not be applicable to the community. There was a dearth of literature regarding the clinicodemographic; and amount and duration of alcohol use. Alcohol abuse is a sensitive issue with some taboo, thus some information may have distorted or concealed.

\section{Conclusion}

The most affected age group was at the peak of their economic and reproductive abilities. Most of the patients were illiterate and jobless. A comprehensive educational awareness program about alcohol use and its effects on the female as a whole, with special attention to pregnancy and lactation is to be undertaken at the community level, with maximum female participation. It is important to recognize and realize that women have unique aspects to their alcohol problems and to understand the complex interplay of roles they have to play in the form of daughter, mother, wife, in-law and manager of the household activities including taking care of children as well as elderly at home and plan accordingly.

\section{References}

1. Singh Sandeep et al. Emotional Competency and Anxiety among Diagnosed Hospitalized Alcoholics: A Psychological Analysis. Journal of Psychological Researches 2005; 49 (1):6-10.

2. World Health Organization (2001). WHO Report 2000 - Mental Health: New Understanding New Hope, Geneva.

3. World Health Organization. Global Status report on Alcohol 2004.

4. World Health Organization. Global Status report on Alcohol. No. 1211. Substance Abuse Department.

5. Core Health Indicators. WHO Statistical Information System (WHOSIS), 2008. WHO publications.

6. Ministry of Health Nepal. Nepal Demographic and Health Survey, 2002

7. Jhingan HP, Shyangwa $P$, Sharma A, Prasad KMR, Khandelwal SK. Prevalence of alcohol dependence in a town in Nepal as assessed by the CAGE 
questionnaire. Addiction. 2003; 98(3): 339-343.

8. Niraula, SR, Shyangwa PM, Jha, N. et al. Alcohol use among Women in town of Eastern Nepal. J Nepal Med Assoc. 2004; 43: 244-249.

9. Nursing Record of Psychiatric Ward. 2064 BS. BPKIHS, Dharan.

10. Shakya DR, Shyangwa P M, Shakya R. Psychiatric Emergencies in a Tertiary Care Hospital. J Nepal Med Assoc. 2008; 47(169):28-33.

11. Sharma A, Khandelwal SK. Women with alcohol-related problems in Nepal. Addiction. 2000; 95(7):1105-1108.

12. P.J. Naga Venkatesha Murthy, Vivek Benegal, Pratima Murthy. Alcohol Dependence in Indian Women: A Clinical Perspective. NIMHANS, Bangalore, India.

13. Central Bureau of Statistics, Nepal: Statistical Pocket Book Nepal, 2002.

14. Shakya DR, 2005. MD thesis. Alcohol Dependence Syndrome.

15. Upadhyaya KD. Alcohol Problems in a community of Western Nepal. Nepalese Journal of Psychiatry. 2001; 2(4):134-138.

16. Dawson DA. General Differences in Alcohol Intake. Research Monologue. National Institute of Alcohol Abuse and Alcoholism. 1995; 29:3-19.

17. Dhital R. 2001. Alcohol \& Drug Use in Nepal CWIN Nepal, Kathmandu.
18. Dawson DA. The link between family history and early onset alcoholim: Earlier initiation of drinking of more rapid dependence? Journal of Studies on Alcohol. 2000; 61:637-646.

19. Capone $C$ and Wood. Density of familial alcoholism and its effects on alcohol use and problems in college students. Alcoholism: Clinical and Experimental Research. 2008; 32: 1451-1458.

20. Zaje A.T. Harrell. Predictors of alcohol problem in college women: The role of depressive symptoms, disordered eating, and family history of alcoholism. Addictive Behaviors. 2009; 34:252-257.

21. Maeng Je Cho et al. Comorbid Mental Disorders among the Patients with Alcohol Abuse and Dependence in Korea. J Korean Med Sci. 2002; 17:23641.

22. Schneider, Donald P.; Richards, Gordon T.; Hall, Patrick B.; Strauss, Michael A.; Anderson, Scott F.; Boroson, Comorbid Anxiety and Affective Disorder in Alcohol-dependent Patients seeking Treatment: The first Multi-Centre study in Germany. Alcohol \& Alcoholism. 2001; 36(3):219-223.

23. Trine Flensborg-Madsen, et al. Amount of Alcohol Consumption and Risk of Developing Alcoholism in Men and Women. Alcohol \& Alcoholism. 2007; 42(5): 442-447. 